Jurnal Sulolipu : Media Komunikasi Sivitas Akademika dan Masyarakat

Vol. 21 No. 12021

e-issn : 2622-6960, p-issn : 0854-624X

\title{
STUDI KANDUNGAN LOGAM BERAT TIMBAL (Pb) PADA BAWANG MERAH (Allium Cepa) DAN SAYUR KUBIS (Brassica Oleracea) (STUDI KEPUSTAKAAN)
}

Study of Lead Heavy Metal Content (Pb) on Shallot (Allium Cepa) and Vegetable Cabbage (Brassica Oleracea) (Literature Study)

Dicky Alamsyah ${ }^{1}$, Muh. Ikbal Arief ${ }^{2}$

${ }^{1}$ Mahasiswa Program Studi Sanitasi Lingkungan, Poltekkes Kemenkes Makassar

2Dosen Poltekkes Kemenkes Makassar

*)dikykesling@gmail.com, 081231821817

\begin{abstract}
Shallots (Allium Cepa) and cabbage (Brassica Oleracea) are horticultural commodities developed and have good prospects classified as spice vegetables. Lead is a bluish soft metal or silvery gray which is commonly found in sulfite deposits mixed with other minerals, especially zinc and copper. This study aims to determine the content of Lead (Pb) in shallots (Allium Cepa) and cabbage (Brassica Oleracea). This type of research is the study of literature, namely by collecting data in the form of secondary data obtained from the literature and the results of previous studies that examine the relationship between independent variables and dependent variables. The sample in this research with literature study was 6 journals related to the title. The results of the study show that there are 3 journals about Lead content $(P b)$ in shallots (Allium Cepa) with average results in journal 1 of 0.0187 ppm, journal 2 of $\leq 0.01$ ppm, journal 3 of $\leq 0,1046$ ppm and 3 journals about lead content (Pb) in cabbage (Brassica Oleracea) with average results in journal 1 of 5.49 ppm, journal 2 of $\leq 0.09$ ppm and in journal 3 of 0.0963 ppm, which is influenced by the use of argochemistry, vehicle smoke, age of the farm used. Based on the results it can be concluded that onion farmers (Allium Cepa) and cabbage vegetables (Brassica Oleracea) should use plant-based pesticides or natural bioactive compounds derived from plants and reduce the dosage of using pesticides and fertilizers.
\end{abstract}

Keywords: Shallot (Allium Cepa), Vegetable Cabbage (Brassica Oleracea), Lead (Pb)

\section{ABSTRAK}

Bawang merah (Allium Cepa) dan sayur kubis (Brassica Oleracea) merupakan komoditi holtikultural yang dikembangkan dan memiliki prospek yang bagus yang tergolong sayuran rempah. Timbal adalah logam lunak kebiruan atau kelabu keperakan yang lazim terdapat dalam kandungan endapan sulfit yang tercampur mineral-mineral lain terutama seng dan tembaga. Penelitian ini bertujuan untuk mengetahui kandungan Timbal $(\mathrm{Pb}$ ) pada bawang merah (Allium Cepa) dan sayur kubis (Brassica Oleracea). Jenis penelitian ini adalah studi literatur, yaitu dengan mengumpulkan data berupa data sekunder yang diperoleh dari literatur-literatur dan hasil penelitian sebelumnya yang mengkaji hubungan variabel bebas dan variabel terikat. Sampel dalam penelitian dengan studi kepustakaan ini adalah 6 jurnal yang sekaitan dengan judul. Hasil dari penelitian menunujukkan bahwa terdapat 3 jurnal tentang kandungan Timbal ( $\mathrm{Pb}$ ) pada bawang merah (Allium Cepa) dengan hasil rata rata pada jurnal 1 sebesar 0,0187 ppm, jurnal 2 sebesar $\leq 0,01$ ppm, jurnal 3 sebesar $\leq 0,1046$ ppm dan 3 jurnal tentang kandungan logam berat timbal $(\mathrm{Pb})$ pada sayur kubis (Brassica Oleracea) dengan hasil rata - rata pada jurnal 1 sebesar 5,49 ppm, jurnal 2 sebesar $\leq 0,09$ ppm dan pada jurnal 3 sebesar 0,0963 ppm, yang dipengaruhi oleh penggunaan argokimia, asap kendaraan, usia lahan pertanian yang digunakan. Berdasarkan hasil dapat disimpulkan bahwa petani bawang merah (Allium Cepa) dan sayur kubis (Brassica Oleracea) sebaiknya menggunakan pestisida nabati atau senyawa bioaktif alamiah yang berasal dari tumbuhan serta mengurangi dosis pemakaian pestisida dan pupuk.

Kata Kunci : Bawang Merah (Allium Cepa), Sayur Kubis (Brassica Oleracea), Timbal (Pb)

\section{Pendahuluan}

Bawang merah (Allium Cepa) merupakan salah satu komoditas pertanian unggulan yang sejak lama telah diusahakan secara intensif oleh petani. Komuditas ini termasuk kedalam kelompok rempah tidak bersubstitusi yang berfungsi sebagai bumbu penyedap makanan serta obat tradisional. (Endarto Ardi 2018).

Sayur kubis ( Brassica Oleracea) merupakan salah satu komuditas holtikultura yang mengandung banyak vitamin dan mineral yang secara langsung meningkatkan kesehatan. Oleh karena itu,higienitas dan keamanan sayuran yang dikonsumsi menjadi sangat penting agar tidak menimbulkan gangguan kesehatan. Namun banyak jenis sayuran yang beredar di masyarakat tidak terjamin keamanannya karena di duga telah terkontaminasi logam-logam berat seperti timbal
$(\mathrm{Pb})$, kadmium $(\mathrm{Cd})$, atau merkuri $(\mathrm{Hg})$ (Astawan 2005).

Indonesia merupakan penghasil bawang merah (Allium Cepa) dan sayur kubis (Brassica Oleracea) dari beberapa provinsi di Indonesia, terdapat enam provinsi penghasil bawang merah dan sayur kubis diantaranya adalah Bima, Nusa Tenggara Timur, Brebes (Jawa Tengah), Jawa Barat, Jawa Timur, Sumatera Utara, dan Sulawesi Selatan.

Produksi bawang merah (Allium Cepa) dan sayur kubis (Brassica Oleracea) di kabupaten Enrekang mengalami peningkatan tiap tahunnya, sehingga penggunaan bahan agrokimia tidak dapat dihindari. Petani di daerah semakin banyak yang menggunakan agrokimia untuk meningkatkan hasil produksi bawang merah (Alliun Cepa) dan sayur kubis (Brassica Oleracea) yang maksimal tampa 
Jurnal Sulolipu : Media Komunikasi Sivitas Akademika dan Masyarakat

Vol. 21 No. 12021

e-issn : 2622-6960, p-issn : 0854-624X

mempertimbangkan akibat yang ditimbulkan pada tanaman dan lingkungan sekitarnya.

Untuk meningkatkan hasil pertanian bawang merah (Allium Cepa) dan sayur kubis (Brassica Oleracea) tentu tidak lepas dari penggunaan pupuk dan bahan agrokimia lainnya. Pupuk merupakan bahan penyubur tanaman yang di berikan pada tanaman agar tumbuh dan berkembang baik. Pupuk phosfat adalah salah satu jenis pupuk anorganik yang saat ini banyak di gunakan oleh petani (Zulvita Aysah 2012).

Pemakaian agrokimia dalam budidaya pertanian tidak dapat dihindarkan, selain keberhasilan yang dicapai, dapat juga menyebabkan akumulasi dan pencemaran pada tanah, tanaman bawang merah (Allium Cepa), sayur kubis (Brassica Oleracea) dan berpengaruh buruk terhadap kesehatan para petai, karena pupuk mengandung logam berat, salah satunya adalah Timbal $(\mathrm{Pb})$.

Pencemaran oleh logam berat merupakan salah satu penyebab penting menurunnya fungsi dan produktifitas tanah. Produk-produk pertanian dituntut mempunyai standar mutu yang baik serta aman dikonsumsi, adanya logam berat dalam tanah pertanian dapat menurunkan produktifitas pertanian dan kualitas hasil pertanian selain dapat membahayakan kesehatan masnusia melalui konsumsi pangan yang dihasilkan dari tanah yang tercemar logam berat timbal $(\mathrm{Pb})$ tersebut.

Konsentrasi timbal $(\mathrm{Pb})$ dalam tanah pertanian di pengaruhi oleh aktifitas disekitarnya, jenis tanah, aliran air, serta kemiringan lahan pertanian tersebut (Sukandarumidi, 2017).

Timbal merupakan bahan yang bersifat karsinogen, beresiko tinggi terhadap tulang, sistem syaraf, pembulu darah, sehingga dapat terakumulasi pada tubuh khususnya otak, ginjal, hati sehingga mengalami disfungsi. Diantaranya penderita yang keracunan timbal mengalami tekanan darah tinggi, nyeri sendi dan otot, kesulitan konsentrasi dan ingatan.(Heryanto Palar,2012).

Dari hasil penelitian zulvita ayza pada tahun 2012, tentang kandungan logam berat timbal (pb) pada bawang merah (allium cepa) hasil pertanian di kecamatan anggeraja kabupaten enrekang. berdasarkan hasil pemeriksaan di balai besar laboratorium kesehatan makassar, di ketahui bahwa lahan pertanian bawang merah mengandung logam berat timbal $(\mathrm{pb})$ yaitu pada tanah dengan usia garapan 1 tahun sebesar 12,2925 ppm, mengalami peningkatan pada usia 10 tahun sebesar $13,7551 \mathrm{ppm}$, akan tetapi mengalami penurunan pada tanah usia garapan 20 tahun sebesar 10,8831 ppm.
Dalam menyuburkan tanaman bawang merah dan sayur kubis penyemprotan dilakukan setiap hari dengan tujuan untuk menghindari serangan hama (ulat) biasanya penyemprotan dilakukan 2 kali sehari. Penyemprotan di lakukan mulai pada umur 8 hari hingga masa panen, dan untuk pemberian pupuk biasanya dilakukan 5 kali pemupukan tiap 1 kali panen.

Keadaan ini selain secara ekonomis,tidak efisien karena harga bahan agrokimia yang terbilang mahal juga dapat menimbulkan dampak negatif bagi lingkungan sepert terakumulasinya zat-zat kimia berbahaya dalam tanah dan kesehatan pekerja serta konsumen.

Mengingat tingginya minat masyarakat dalam mengonsumsi bawang merah (Allium Cepa) dan sayur kubis (Brassica Oleracea) dan penggunaan bahan agrokimia yang tidak sesuai dengan dosis dan frekuensi pemakaiannya serta bahaya logam berat timbal $(\mathrm{Pb})$ terhadap kesehatan, maka peneliti tertarik untuk melakukan penelitian dengan judul "Studi Kandungan Logam Berat (Pb) Pada Bawang Merah (Allium Cepa) dan Sayur Kubis (Brassica Olerace)".

\section{Metode \\ Jenis Penelitian}

Jenis penelitian ini adalah penelitian deskriptif yang bersifat studi kepustakaan (library research) yaitu sebuah pencarian literatur seperti jurnal, majalah, buku-buku pengetahuan, dan lain sebagainya yang relevan dengan kandungan logam berat timbal $(\mathrm{Pb})$ pada bawang merah dan sayur kubis sebagai objek yang utama.

\section{Waktu Penelitian}

Waktu dalam penelitian ini terbagi dua (2), yaitu:

a. Tahapan persiapan yaitu pengambilan data sekunder untuk mengumpulkan literatur, untuk kepentingan penyusunan proposal yang dilaksanakan pada bulan Desember 2019 - Januari 2020.

b. Tahap penelitian pelaksanaan kegiatan penelitian dilaksanakan pada bulan April Mei 2020.

\section{Pengumpulan data}

Teknik pengumpulan data dalam penelitian ini yaitu data sekunder. Data sekunder adalah data yang diperoleh dari buku - buku, internet, dan hasil penelitian lainnya yang berhubungan dengan objek penelitian.

\section{Analisis Data}

Teknik analisis data yang digunakan pada penelitian ini adalah menganalisa data dengan teknik analisis isi (Content Analisis). Analisis isi adalah penelitian yang bersifat pembahasan yang mendalam terhadap isi suatu informasi 
Jurnal Sulolipu : Media Komunikasi Sivitas Akademika dan Masyarakat

Vol. 21 No. 12021

e-issn : 2622-6960, p-issn : 0854-624X

tertulis atau tercetak di media, membandingkan, menggabungkan, dan memilih sebagai pengertian sehingga ditemukan yang relevan.

\section{Hasil dan Pembahasan \\ Hasil}

Tabel 1

Zulvita Aisyah, 2012 Kandungan Logam Berat

Timbal (Pb) Pada Bawang Merah (Allium Cepa)

Hasil Pertanian di Kecmatan Anggeraja Kabupaten Enrekang

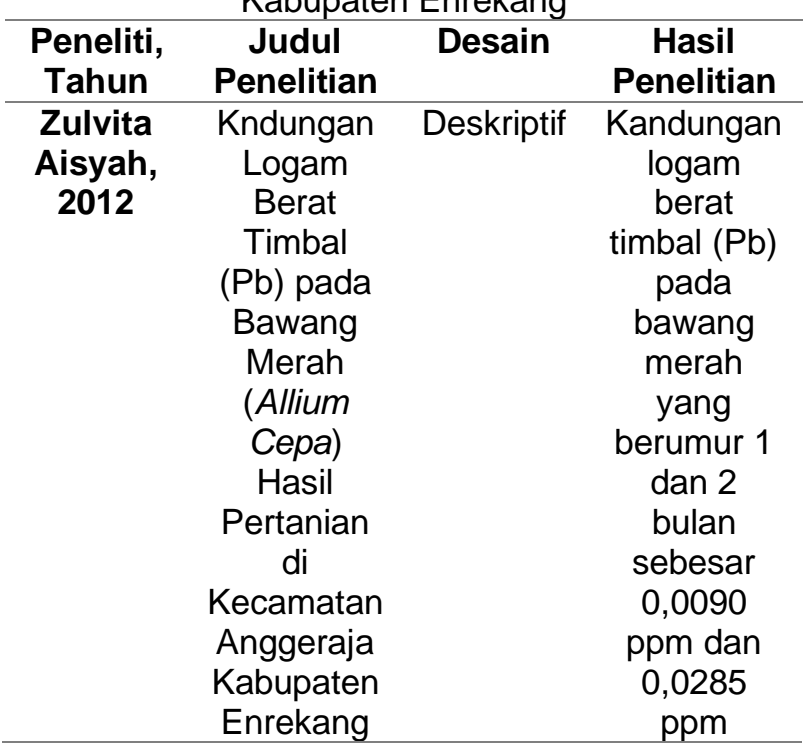

Tabel 3

Hasmayani, 2018 Faktor - Faktor yang

Mempengaruhi Kandungan Timbal (Pb)Pada

Bawang Merah (Allium Cepa) di Desa

Pekalobean Kabupaten Enrekang

\begin{tabular}{|c|c|c|c|}
\hline $\begin{array}{l}\text { Peneliti, } \\
\text { Tahun }\end{array}$ & $\begin{array}{c}\text { Judul } \\
\text { Penelitian }\end{array}$ & Desain & $\begin{array}{c}\text { Hasil } \\
\text { Peneliti } \\
\text { an }\end{array}$ \\
\hline $\begin{array}{c}\text { Hasmay } \\
\text { ani, } 2018\end{array}$ & $\begin{array}{c}\text { Faktor- } \\
\text { Fakto yang } \\
\text { Mempenga } \\
\text { ruhi } \\
\text { Kandungan } \\
\text { Timbal (Pb) } \\
\text { Pada } \\
\text { Bawang } \\
\text { Merah } \\
\text { (Allium } \\
\text { Cepa) di } \\
\text { Desa } \\
\text { Pekalobea } \\
\text { n } \\
\text { Kabupaten } \\
\text { Enrekang }\end{array}$ & $\begin{array}{c}\text { Observasi } \\
\text { onal } \\
\text { Deskriptif }\end{array}$ & $\begin{array}{c}\text { Kandung } \\
\text { an } \\
\text { Logam } \\
\text { berat } \\
\text { timbal } \\
(\mathrm{Pb}) \\
\text { pada } \\
\text { bawang } \\
\text { merah } \\
\text { dengan } \\
\text { jumlah } 6 \\
\text { sampel } \\
\text { yang di } \\
\text { periksa } \\
\text { dapatka } \\
\mathrm{n} \text { hasil } \\
\text { degan } \\
\text { rata - } \\
\text { rata } \\
0,1046 \\
\text { ppm. }\end{array}$ \\
\hline
\end{tabular}

Tabel 2

Kurniati, 2017 Kandungan Logam Berat Timbal

(Pb) Dalam Residu Pestisida Pada Tanah, Air, dan Bawang Merah di Desa Salu

DewataKecamatan Anggeraja Kabupaten

\begin{tabular}{cccc}
$\begin{array}{c}\text { Peneliti, } \\
\text { Tahun }\end{array}$ & $\begin{array}{c}\text { Judul } \\
\text { Penelitian }\end{array}$ & Desain & $\begin{array}{c}\text { Hasil } \\
\text { Penelitian }\end{array}$ \\
\hline Kurniati, & Kandungan & Survei & kandungan \\
2017 & Logam & Deskriptif & timbal $(\mathrm{Pb})$ \\
& Berat & & pada \\
& bawang \\
& Timbal & & merah \\
& (Pb) Dalam & pada usia \\
Residu & tanah \\
& Pestisida & garapan \\
pada & 10,20 , dan \\
Tanah, Air, & 25 tahun \\
dan & yaitu $\leq$ \\
Bawang & 0.01 ppm \\
Merah di & \\
Desa Salu & \\
Dewata & \\
Kecamatan & \\
Anggeraja & \\
Kabupaten & \\
Enrekang & \\
\hline
\end{tabular}

Tabel 4

Chyntia Arkesti Pasaribu, Sarifuddin, Posma

Marbun, 2015, Kandungan Logam Berat Pb

Pada Kol dan Tomat di Berbagai Kecamatan Kabupaten Karo

\begin{tabular}{llll}
$\begin{array}{c}\text { Peneliti, } \\
\text { Tahun }\end{array}$ & $\begin{array}{c}\text { Judul } \\
\text { Penelitian }\end{array}$ & Desain & $\begin{array}{c}\text { Hasil } \\
\text { Penelitian }\end{array}$ \\
\hline Chyntia & Kandungan & Survei & Kadar Pb \\
Arkesti & Logam & Analisis & daun kol \\
Pasaribu, & Berat Pb & & pada jarak \\
Sarifuddin, & Pada Kol & $5 \mathrm{~m}$ dan \\
Posma & dan Tomat & $10 \mathrm{~m}$ \\
Marbun, & di Berbagai & tanpa \\
$\mathbf{2 0 1 5}$ & Kecamatan & pencucian \\
& Kabupaten & masing- \\
& Karo & masing \\
& & 6,19 ppm \\
& & dan 4,79 \\
& & ppm dan \\
& & dengan \\
& & pencucian \\
& & 4,48 ppm \\
& & dan 3,86 \\
& & ppm \\
\hline
\end{tabular}


Jurnal Sulolipu : Media Komunikasi Sivitas Akademika dan Masyarakat

Vol. 21 No.12021

e-issn : 2622-6960, p-issn : 0854-624X

Tabel 5

Sartika Fergina Ruhut, D.M.F Sumampow, Wiske Rotinsuhu, 2018, Analisis Konsentrasi Timbal Pada

Tanaman Kubis (Brassica Oleracea) di Kota Tomohon

\begin{tabular}{|c|c|c|c|}
\hline $\begin{array}{c}\text { Peneliti, } \\
\text { Tahun }\end{array}$ & $\begin{array}{c}\text { Judul } \\
\text { Penelitian }\end{array}$ & Desain & $\begin{array}{c}\text { Hasil } \\
\text { Penelitian }\end{array}$ \\
\hline $\begin{array}{c}\text { Sartika } \\
\text { Fergina } \\
\text { Ruhut, } \\
\text { D.M.F } \\
\text { Sumampow } \\
\text {, Wiske } \\
\text { Rotinsuhu, } \\
2018\end{array}$ & $\begin{array}{c}\text { Analisis } \\
\text { Konsentras } \\
\text { i Timbal } \\
\text { Pada } \\
\text { Tanaman } \\
\text { Kubis } \\
\text { (Brassica } \\
\text { Oleracea) } \\
\text { di Kota } \\
\text { Tomohon }\end{array}$ & $\begin{array}{l}\text { Purposiv } \\
\text { e } \\
\text { Sampling }\end{array}$ & $\begin{array}{c}\text { Hasil analisa } \\
\text { menunjukka } \\
\text { n bahwa } \\
\text { konsentrasi } \\
\text { timbal } \\
\text { sebesar } \\
<0,09 \text { ppm } \\
\text { pada } \\
\text { tanaman } \\
\text { kubis di } \\
\text { pinggir jalan } \\
\text { raya (PJR) } \\
\text { sama } \\
\text { dengan } \\
\text { lokasi jauh } \\
\text { dari jalan } \\
\text { raya (JDJR). }\end{array}$ \\
\hline
\end{tabular}

Tabel 6

Siti Noviani Ulfa, 2018 Uji Kandungan Logam Berat Timbal $(\mathrm{Pb})$ pada Sayur Kubis (Brassica Oleracea) Yang Ditanam di Pinggir Jalan Desa Pasangrahan Kecamatan Montong Gading Kabupaten Lombok Timur Dalam Upaya Pembuatan Brosur Masyarakat.

\begin{tabular}{|c|c|c|c|}
\hline $\begin{array}{l}\text { Peneliti } \\
\text {, Tahun }\end{array}$ & $\begin{array}{c}\text { Judul } \\
\text { Penelitian }\end{array}$ & Desain & $\begin{array}{c}\text { Hasil } \\
\text { Penelitian }\end{array}$ \\
\hline $\begin{array}{l}\text { Siti } \\
\text { Noviani } \\
\text { Ulfa, } \\
2018\end{array}$ & $\begin{array}{c}\text { Uji } \\
\text { Kandungan } \\
\text { Logam Berat } \\
\text { Timbal (Pb) } \\
\text { pada } \\
\text { Sayuran } \\
\text { Kubis } \\
\text { (Brassica } \\
\text { Oleraceae) } \\
\text { yang } \\
\text { Ditanam di } \\
\text { Pinggir Jalan } \\
\text { Desa } \\
\text { Pesanggraha } \\
\text { n Kecamatan } \\
\text { Montong } \\
\text { Gading } \\
\text { Kabupaten } \\
\text { Lombok } \\
\text { Timur dalam } \\
\text { Upaya } \\
\text { Pembuatan } \\
\text { Brosur } \\
\text { Masyarakat }\end{array}$ & $\begin{array}{l}\text { Observasion } \\
\text { al Deskriptif }\end{array}$ & $\begin{array}{c}\text { Kandunga } \\
\mathrm{n} \text { Logam } \\
\text { Berat } \\
\text { timbal } \\
(\mathrm{Pb}) \text { pada } \\
\text { sayur } \\
\text { kubis } \\
\text { dengan } \\
\text { jarak } \\
\text { tanam } 5 \\
\text { meter dari } \\
\text { jalan yaitu } \\
0.1652 \\
\text { ppm, } \\
\text { kemudian } \\
\text { pada jarak } \\
2 \text { meter } \\
\text { yaitu } \\
0.1032 \\
\text { ppm dan } \\
\text { pada jarak } \\
8 \text { meter } \\
\text { yaitu } \\
0.0207 \\
\text { nnm }\end{array}$ \\
\hline
\end{tabular}

\section{Pembahasan}

1. Kandungan Logam Berat Timbal (Pb) Pada Bawang Merah (Allium Cepa)

Berdasarkan jurnal yang dikaji pada tabel 1 dengan judul Kandungan logam berat timbal $(\mathrm{Pb})$ pada bawang merah (Allium Cepa) hasil pertanian di kecamatan Anggeraja kabupaten Enrekang dengan metode penelitian deskriptif di dapatkan hasil kandungan logam berat timbal $(\mathrm{Pb})$ pada bawang merah yaitu kandungan ratarata pada bawang merah yang berumur 1 bulan dan 2 bulan sebesar 0,0090 ppm dan 0,0285 ppm.

Adanya kandungan logam berat timbal $(\mathrm{Pb})$ tersebut pada bawang merah dikarenakan usia tanah garapan, penggunaan bahan agrokimia (pupuk dan pestisida), serta usia dari bawang merah tersebut.Usia tanah garapan tersebut sangan berpengaruh terhadap kandungan logam berat timbal $(\mathrm{Pb})$ karena semakin tua usia tanah garapan maka akan semakin banyak residu pestisida yang terakumulasi dalam tanah dan akan terserap oleh tanaman hal ini didukung oleh hasil penelitian Karyadi, dkk pada tahun 2011 di kabupaten Kendal dimana dalam satu musim tanam dapat menyumbang $\mathrm{Pb}$ dalam tanah sebanyak 2991,26 mg/Ha.

Pada jurnal ke 2 di tabel 2 dengan judul penelitian kandungan logam berat timbal (Pb) dalam residu pestisida pada tanah, air, dan bawang merah di Desa Salu Dewata Kecamatan Anggeraja Kabupaten Enrekang dengan metode peneltian survei deskriptif di dapatkan hasil kandungan logam berat timbal $(\mathrm{Pb})$ pada bawang merah dengan usia tanah garapan 10,20, dan 25 tahun yaitu $\leq 0.01 \mathrm{ppm}$.

Keberadaan kandungan logam berat timbal $(\mathrm{Pb})$ dalam umbi bawang merah tersebut dikarenakan tingginya residu pestisida dalam tanah garapan sehingga ikut terserap oleh tanaman bawang merah tersebut.

Sedangkan pada jurnal 3 di tabel 3 dengan judul penelitian faktor - faktor yang mempengaruhi kandungan timbal $(\mathrm{Pb})$ pada bawang merah (Allium cepa) di Desa Pekalobean Kabupaten Enrekang dengan metode penelitian Observasional Dskriptif di dapatkan kandungan logam berat timbal $\mathrm{Pb}$ ) pada bawang merah degan rata - rata 0,1046 ppm.

Tingginya kandungan logam berat timbal $(\mathrm{Pb})$ pada bawang merah tersebut dikarenakan penggunaan pestisida dan 
Jurnal Sulolipu : Media Komunikasi Sivitas Akademika dan Masyarakat

Vol. 21 No. 12021

e-issn : 2622-6960, p-issn : 0854-624X

pupuk yang mengandung logam berat timbal di Desa Pekalobean. Dimana pestisida yang digunakan yaitu Antracol WP sebesar 12,4800 ppm, Dithane M 4580 WP 19,3710 ppm dan Buldok 25 EC 2,0420 ppm. Dan pupuk mengandung timbal $(\mathrm{Pb})$ yaitu Urea sebanyak 4,4511 ppm dan Nitro Ponska 2,1620 ppm.

Kandungan logam berat timbal $(\mathrm{Pb})$ pada bawang merah dari ke 3 jurnal tersebut dapat di ketahui bahwa pada jurnal ke 3 kandungan logam berat timba $(\mathrm{Pb})$ sebesar 0,1046 ppm dimana sudah melebihi ambang batas menurut Peraturan Menteri Pertanian Republik Indonesia Nomor 04 / Permentan / PP.340 / 2 / 20 / 2015. Standar yang di perbolehkan yaitu $0,1 \mathrm{mg} / \mathrm{kg}$. sehingga tidak layak dikonsumsi karena dapat berdampak buruk terhadap kesehatan petani dan konsumen.

Keberadaan logam berat timbal $(\mathrm{Pb})$ dalam umbi bawang merah disebabkan dari beberapa faktor seperti penggunaan argokimia (pupuk dan pestisida), asap kendaraan bermotor, serta lahan pertanian yang digunakan. Karena penggunaan bahan agrokimia secara terus-menerus dapat mengakibatkan akumulasi timbal $(\mathrm{Pb})$ pada tanah pertanian, jarak lahan pertanian yang dekat dari jalan raya memungkinkan logam berat $(\mathrm{Pb})$ dari hasil buangan asap kendaraan bermotor dapat mencemari tanah pertanian dan juga usia lahan pertanian yang digunakan, karena semakin lama tanah terpapar oleh pestisida dan pupuk akan meninggalkan residu logam berat pada tanah semakin besar yang akan terakumulasi kedalam umbi bawang merah tersebut.

Adanya kandungan timbal $(\mathrm{Pb})$ pada tanah dan bawang merah (Allium Cepa) tergantung sifat dan faktor serta kondisi lingkungan masing-masing sampel yang dapat mempengaruhi sampel itu sendiri. Karena semakin tinggi kandungan logam berat dalam tanah maka semakin tinggi pula akumulasi timbal $(\mathrm{Pb})$ dalam umbi bawang merah. faktor yang menyebabkan keberadaan kandungan logam berat dalam bawang merah menurut Alloway, 1990 dalam Anita E 2003, unsur logam berat timbal $(\mathrm{Pb})$ di dalam tanah akan terdifusi secara positif melalui lapisan endodermis pada akar tanaman. Akumulasi timbal $(\mathrm{Pb})$ terjadi pada lapisan endodermis tanaman tersebut dan terjadi proses detoksifikasi oleh fitokelatin di dalam sitoplasma. Unsur timbal $(\mathrm{Pb})$ bersama unsur hara lainnya kemudian ditranslokasikan ketajuk tanaman hingga sampai di daun melalui xilem pada proses fotosintesis.

Kandungan timbal (Pb) pada tanah disebabkan karena penggunaan agrokimia (pupuk dan pestisida) yang digunakan oleh petani bawang merah. Salah satunya adalah pupuk phosfat yang mengandung timbal $(\mathrm{Pb})$ cukup besar. Hampir semua petani menggunakan dosis pestisida dan pupuk yang tinggi dalam membunuh hama penyakit pada tanaman terutama pada bawang merah tersebut. adanya hubungan yang sangat kuat antara variabel dosis pestisida, jenis bahan agrokimia terhadap tambahan logam berat $\mathrm{Pb}$. Frekuensi penyemprotan, dosis pestisida, jenis bahan agrokimia dan variabel kandungan $\mathrm{Pb}$ yang terkandung didalamnya terbukti berpengaruh sangat signifikan terhadap tambahan logam berat $\mathrm{Pb}$ dalam tanah dan tanaman.

Penggunaan dosis pestisida dan pupuk mempengaruhi kandungan timbal $(\mathrm{Pb})$ pada bawang merah (Allium Cepa). Dimana jenis dan jumlah pestisida yang digunakan oleh petani berbeda-beda, dan pada umumnya mencampur 8-15 macam pestisida. Sedangkan untuk penggunaan pupuk mencampur 5-8 jenis pupuk. Para petani menggunakan pestisida dengan dosisi tinggi saat tanaman terserang organisme pengganggu tanaman agar dapat mematikan organisme pengganggu tanaman. Padahal dapat merugikan para petani sendiri dari segi biaya menjadi boros dan membuat residu logam berat dan pestisida semakin banyak di lingkungan yang berdampak negatif pada tanaman. Karena dengan adanya kandungan timbal ( $\mathrm{Pb}$ ) pada bawang merah (Allium Cepa) dapat memberi efek yang tidak baik bagi kesehatan manusia. Seperti yang diketahui bahwa seberapa pun kandungan logam berat yang terdeteksi dalam makanan akan berbahaya, karena terjadi proses bioakumulasi pada tubuh manusia yang mengonsumsinya.

2. Kandungan Logam Berat Timbal (Pb) Pada Sayur Kubis (Brassica Oleraceae)

Berdasarkan jurnal 1 yang dikaji pada tabel 4 dengan judul penelitian kandungan logam berat $\mathrm{Pb}$ pada $\mathrm{kol}$ dan tomat di berbagai kecamatan Kabupaten Karo dengan desain penelitian Survei Analisis didapatkan hasil kandungan logam berat timbal $(\mathrm{Pb})$ pada daun kol pada jarak $5 \mathrm{~m}$ dan $10 \mathrm{~m}$ tanpa pencucian masing-masing 
Jurnal Sulolipu : Media Komunikasi Sivitas Akademika dan Masyarakat

Vol. 21 No. 12021

e-issn : 2622-6960, p-issn : 0854-624X

6,19 ppm dan 4,79 ppm dan dengan pencucian 4,48 ppm dan 3,86 ppm.

Adanya kandungan logam berat timbal pada sayur kubis tersebut di sebabkan oleh sisa asap dari kendaraan bemotor dimana dapat dilihan dari hasil pemeriksaan menyatakan bahwa semakin dekat jarak sampel dari jalan raya maka semakin tinggi kandungan logam berat dari sayur kubis tersebut. Hal ini didukung oleh Siregar (2005) yang menyatakan semakin tinggi tingkat pencemaran akan menyebabkan semakin tinggi kadar $\mathrm{Pb}$ dalam sayuran.

Pada jurnal ke 2 di tabel 5 dengan judul Analisis konsentrasi timbal pada tanaman kubis (Brassica Oleracea) di kota Tomohon dengan desain penelitian Purposive Sampling didapatkan hasil kandungan logam berat timbal $(\mathrm{Pb})$ pada sayur kubis (Brassica Oleracea) sebesar $<0,09$ ppm.

Adanya Logam berat seperti timbal $(\mathrm{Pb})$ terdeteksi pada sayuran seperti kubis, terutama yang ditanam dekat dengan jalan raya dan rentan polusi udara, antara lain yang berasal dari asap pabrik serta asap kendaraan bermotor. Menurut Widaningrum dkk, (2007) Sayuran sebagai salah satu komoditas hortikultura, memiliki potensi untuk dikembangkan pada areal pertanian kota dan pinggiran kota. Namun sayursayuran berdaun yang ditanam di pinggir jalan raya memiliki resiko terpapar logam berat yang cukup tinggi seperti halnya tanaman kubis.

Konsentrasi timbal $(\mathrm{Pb})$ pada pertanaman kubis di Tomohon terdeteksi dengan nilai konsentrasi yang masih dibawah standar cemaran logam berat atau masih dibawah batas maksimum. Adanya sedikit konsentrasi timbal $(\mathrm{Pb})$ pada pertanaman kubis di pinggir jalan raya dan jauh dari jalan raya Kota Tomohon dikarenakan oleh beberapa faktor seperti dapat berasal kontaminasi dari asap kendaraan bermotor yang selanjutnya akan masuk ke dalam siklus pertumbuhan tanaman kubis

Sedangkan pada jurnal ke 3 di tabel 5 dengan dengan judul penelitian Uji Kandungan Logam Berat Timbal $(\mathrm{Pb})$ pada Sayuran Kubis (Brassica Oleraceae) yang Ditanam di Pinggir Jalan Desa Pesanggrahan Kecamatan Montong Gading Kabupaten Lombok Timur dalam Upaya Pembuatan Brosur Masyarakat dengan metode penelitian Observasional Deskriptif didapatkan hasil kandungan logam berat timbal $(\mathrm{Pb})$ dengan jarak tanam 2 meter $=$ $0,1032 \mathrm{ppm}, 5$ meter $=0,1652 \mathrm{ppm}$, dan 8 meter $=0,0207 \mathrm{ppm}$.

Konsentrasi logam berat timbal yang paling banyak terdapat pada sayuran kubis dengan jarak tanam 5 meter dari jalan, hal ini dikarenakan pada jarak tersebut lebih dekat dengan jalan raya dan tidak dipengaruhi oleh tumbuhan apapun yang berada di sekitarnya. Konsentrasi logam berat timbal yang paling sedikit terdapat pada sayuran kubis dengan jarak 8 meter dari jalan, hal ini dikarenakan sayuran kubis dengan jarak tersebut paling jauh dari jalan raya. Konsentrasi logam berat timbal pada jarak 2 meter dari jalan raya lebih sedikit daripada dengan jarak 5 meter dari jalan raya, dikarenakan di sekitar tanaman kubis tersebut terdapat pohon-pohon besar peneduh jalan yang memungkinkan logam berat timbal yang ada di udara ikut terserap dan terjerap oleh pohon tersebut.

Berdasarkan 3 jurnal yang dikaji tersebut dapat dilihat bahwa kandungan logam berat timbal $(\mathrm{Pb})$ pada sayur kubis tersebut sudah melebihi ambang batas menurut Peraturan Menteri Pertanian republik Indonesia Nomor 04 / Permentan / PP.340 / 2 / 2015. Standar yang di perbolehkan yaitu $0,3 \mathrm{mg} / \mathrm{kg}$. sehingga tidak layak dikonsumsi karena dapat berdampak buruk terhadap kesehatan petani dan konsumen.

Adanya kandungan logam berat timbal $(\mathrm{Pb})$ pada sayur kubis (Brassica Oleracea) yang ditanam dengan jarak yang sangat dekat dari jalan raya mempunyai nilai kadar logam berat timbal $(\mathrm{Pb})$ yang tertinggi. Hal ini dikarenakan sampel sayur kubis yang diambil dipengaruhi oleh gas sisa buangan kendaraan bermotor dari jalan raya. Penelitian ini didukung oleh Siregar (2005) yang menyatakan semakin tinggi pencemaran akan menyebabkan semakin tinggi kadar $\mathrm{Pb}$ dalam sayuran.

Menurut Darmono (2001) menyatakan bahwa sumber kontaminasi logam dalam tanah pertanian berasal dari: (1) Jumlah logam yang ada pada batuan tempat tanah terbentuk, (2) Jumlah pupuk yang diberikan, (3) Berasal dari berbagai kegiatan seperti pertambangan, industri dan transportasi yang sering ditemukan dalam air, tanah dan udara, (4) Jumlah yang terambil pada proses panen ataupun merembes ke dalam tanah yang lebih dalam.

Konsentrasi timbal yang terdapat pada sayur kubis dikarenakan adanya 
Jurnal Sulolipu : Media Komunikasi Sivitas Akademika dan Masyarakat

Vol. 21 No.12021

e-issn : 2622-6960, p-issn : 0854-624X

pencemaran timbal $(\mathrm{Pb})$ baik di udara maupun dari tanah, yaitu pada asap kendaraan serta pencemaran logam berat terjadi selama proses prapanen yaitu selama penanaman dan pemeliharaan, juga disebabkan pemakaian pupuk yang mengandung logam berat timbal $(\mathrm{Pb})$.

\section{Kesimpulan dan Saran \\ Kesimpulan}

Berdasarkan hasil studi kepustakaan diatas diketahui bahwa adanya kandungan logam berat timbal $(\mathrm{Pb})$ bawang merah (Allium Cepa) dan sayur kubis (Brassica Oleracea) yang disebabkan ole faktor penggunaan bahan agrokimia, sisa asap buangan kendaraan, dan usia tanah garapan pertanian.

\section{Saran}

1. Diharapkan kepada pemerintah untuk memberikan penyuluhan kepada para petani bawang merah dan sayur kubis tentang penggunaan bahan aggrokimia yang baik dan benar sesuai dengan anjura yang di bolehkan.

2. Diharapkan kepada pemerintah untuk memproduksi pupuk dan pestisida nabati yang lebih ramah lingkungan sebagai pengganti pupuk dan pestisida kimia.

3. Diharapkan kepada para petani bawang merah dan sayur kubis supaya menggunakan pupuk dan pestisida nabati sebagai alternatif pengganti pupuk dan pestisida kimia, sehingga tidak meninggalkan residu di lingkungan.

4. Diharapkan kepada para petani agar kiranya tidak menanam bawang merah dan sayur kubis ditempat dekat dengan jalan raya.

5. Diharapkan kepada para masyarakat agarkiranya sebelum mengonsumsi hasil pertanian untuk mencuci/membersihkan terlebih dahulu hasil pertaniannya

\section{PUSTAKA}

Anita evi. 2003. Penyebaran Timbal Pada Tanah Aluvial Brebes dengan Tanaman Indikator Bawang Merah. (SKRIPSI), Bogor: Fakultas Matematika dan Ilmu Pengetahuan Alam Institusi Pertanian Bogor (Online)http://www.kib.org.tr/files/downloads/sirkuler/2016241ek3.pdf. (Diakses pada tgl 09 Januari 2020)

Ardi Endarto. 2018. Bawang Merah Teknik Budidaya dan Peluang usahanya. Yogyakarta: Transa Idea Publising.

Astawan, M. 2005. Bahaya kontaminasi Logam Berat Dalam Sayuran dan Alternatif Pencegahan Pencemarannya. Buletin Teknologi Pasca Panen Pertanian 1(3):16-27.

Aysah Zulvita. 2012. Kandungan Logam Berat Timbal (Pb) pada bawang merah (Allium Cepa) Hasil Pertanian di Kecamatan Anggeraja Kabupaten Enrekang.(KTI) Makassar: Politeknik Kesehatan Makassar Jurusan Kesehatan Lingkungan.

Darmono. 2001. Lingkungan Hidup dan Pencemarannya: hubungan dengan Toksiologi Senyawa Logam Berat. Universitas Indonesia Press. Jakarta. 179 hal.

Heryanto Palar. 2012. Pencemaran dan Toksilogi Logam Berat. Jakarta: Rineka Cipta

Notoatmojo Soekidjo. 2018. Metodologi Penelitian Kesehatan. Jakarta: Rineka Cipta.

Peraturan Menteri Pertanian RI NO. 04 / Permentan / PP.340/2/2015. http://www.kib.org.tr/files/downloads/sirkuler/2016241ek3.pdf. (Diakses pada tgl 09 Januari 2020).

Sahani Wahyuni, dkk 2019 "Panduan Penulisan Proposal Penelitian dan Skripsi" Makassar: Jurusan Kesehatan Lingkungan: Politeknik Kesehatan Kemenkes Makassar.

Siregar, E. B. M. 2005. Pencemaran Udara, Respon Tanaman dan Pengaruhnya pada Manusia. Skripsi. Fakultas Pertanian. USU. Medan

Sukandarrumidi. 2017. Geotoksikologi. Jakarta:Gadjah Mada University Press.

Widaningrum, dkk, 2007. Bahaya Kontaminasi Logam Berat dalam Sayuran dan Alternatif

Pencegahan Cemarannya.Buletin TeknologiPascapanen Pertanian 3 (16-27) 